\title{
Management of chronic postoperative surgical pain (CPSP) following appendicectomy
}

\author{
S Parthasarathy ${ }^{1^{*}}$, G Naveenkumar ${ }^{2}$ \\ Associate Professor ${ }^{1 *}$, Postgraduate student ${ }^{2}$, Mahatma Gandhi Medical College and Research \\ Institute, Puducherry, India.
}

\begin{abstract}
A 35-year-old female presented with severe pain at the appendicectomy scar site of six months duration. She had an open appendicectomy done followed by continuous pain from the time of discharge. She was diagnosed as a case of chronic post surgical pain syndrome (CPSP). We administered transversus abdominis plane block (TAP) by ultrasound guidance depositing bupivacaine $0.25 \% 20 \mathrm{ml}$ and intralesional $80 \mathrm{mg}$ methylprednisolone as a depot preparation. The visual analogue score showed significant improvement from $7 / 10$ to $1 / 10$ for the next five months of follow up. We conclude that USG guided TAP block combined with intralesional steroid is a viable treatment option in cases of CPSP.
\end{abstract}

Keywords: Post-operative; chronic pain; plane block; steroid

\section{Introduction}

Chronic post surgical pain syndrome (CPSP) is defined based on four criteria.

- The pain should have developed after a surgical procedure

- The pain should be of at least 2 months' duration.

- Other causes of the pain should be excluded, such as recurrence of malignancy or infection.

- The possibility that the pain is continuing from a pre-existing problem should be explored and exclusion attempted. ${ }^{1}$

Various factors including surgical, psychological, amount of acute pain relief have been proposed as risk factors for developing CPSP. ${ }^{2}$ A number of patients suffer due to a lack of awareness of the condition. Different treatment modalities like nerve and plane blocks, intralesional steroid and psychiatric counselling have been described to counter this pain. We describe a case of successful management of a post appendicectomy CPSP with combined Transversus abdominis plane (TAP) block and intralesional steroids.

*Correspondence: S Parthasarathy

E mail: painfreepartha@gmail.com

(iD) https://orcid.org/0000-0002-3808-6722

Received: 17/09/2017

Accepted: 06/10/2017

DOI: http://doi.org/10.4038/slja.v26i1.8277

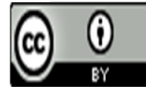

\section{Case report}

A 35-year-old female came to our hospital complaining of pain over the right lower abdomen for the past six months, which was insidious in onset, progressive in nature and present throughout the day. This was a dull aching pain not relieved with routine analgesics. There were no associated symptoms such as abdominal distension, vomiting, constipation, fever or trauma. There was no similar illness in the past. She underwent an open appendicectomy around six months ago under subarachnoid block followed by continuous symptoms. A thorough clinical examination was normal. Examination of the surgical scar showed mild hyperalgesia without allodynia. She had already been subjected to routine blood investigations, an ultrasound abdomen and contrast enhanced CT abdomen which were normal. Prior to reporting to us, she had undergone a negative diagnostic laparoscopy. She was now diagnosed as chronic post surgical pain syndrome (CPSP). The patient's pain was assessed by visual assessment scoring system and was noted to be 7/10. We administered TAP block on the right side with $20 \mathrm{ml}$ of $0.25 \%$ bupivacaine along with intralesional steroid injection of depot preparation of methyl prednisolone of $80 \mathrm{mg}$. After $15 \mathrm{mins}$ of drug administration the patient was completely symptom free and was discharged. The patient was followed up for the next five months and the visual analogue score was analyzed each month and it was $1 / 10$. There were no complications. 


\section{Discussion}

Postoperative complications following appendicectomy are uncommon and reflect the degree of peritonitis that was present at the time of operation, intra-operative spillage and inter current diseases that predispose to complications. Wound infection is the most common postoperative complication. ${ }^{2}$ Our patient was a case of interval appendicectomy with neither infection nor intercurrent illness. In our case, we had all the four criteria of CPSP fulfilled. The incidence of CPSP is very variable and roughly between $30-35 \%$ after general surgery. ${ }^{3} \mathrm{~A}$ high index of suspicion and awareness about this condition is warranted. Transversus abdominis plane (TAP) block involving the nerves of the anterior abdominal wall has been developed for post-operative pain control after gynaecologic and abdominal surgery. Its use in the management of CPSP has also been described. ${ }^{4}$ So in our case we used the TAP block with bupivacaine. Intralesional corticosteroid (CS) injections have been used to treat a variety of dermatological and non-dermatological diseases with variable results. The main purpose of the injection is to attain a high local concentration of the steroid at the operated site, without significant systemic absorption, thus avoiding numerous side-effects. We used the depot preparation to improve the outcome of the patient with decreased side effects. CS has not been described for this entity, yet we wanted to utilize its benefits in scar treatment strategies. ${ }^{5}$ Hence after giving combined treatment in a single sitting, the visual analogue score improved immediately from $7 / 10$ to $1 / 10$ which persisted for the next 6 months of follow up of the patient. The limitations are that we didn't analyse the effectiveness of individual treatment options and it's only a single case report.

\section{Conclusion}

Chronic post surgical pain (CPSP) is a definite clinical entity after appendicectomy. We report a successful management of such a case with combined ultrasound guided transversus abdominis plane block and intralesional corticosteroid. The patient had very significant pain relief for the next five months follow up without any side effects.

\section{References}

1. Macre WA. Chronic pain after surgery. Br.JAnaesth2001;87:88-98 https://doi.org/10.1093/bja/87.1.88
2. Margenthaler JA, Longo WE, Virgo KS, et al. Risk Factors for Adverse Outcomes After the Surgical Treatment of Appendicitis in Adults. Annals of Surgery 2003;238(1):59-66. https://doi.org/10.1097/01.SLA.0000074961.500 $\underline{20 . f 8}$

PMid:12832966 PMCid:PMC1422654

3. Simanski CJ, Althaus A, Hoederath S, et al. Incidence of chronic postsurgical pain (CPSP) after general surgery. Pain Med. 2014; 15(7):1222-9 https://doi.org/10.1111/pme.12434 PMid:24716774

4. Lamichhane D, Yang XL, Ma ZL. Effect of Transverse Abdominis Plane Block on Chronic Post-Operative Pain-A Review. Open Journal of Anesthesiology2017;7: 23-34

https://doi.org/10.4236/ojanes.2017.72003

5. Gauglitz GG. Management of keloids and hypertrophic scars: current and emerging options. Clinical, Cosmetic and Investigational Dermatology 2013;6:103-114. https://doi.org/10.2147/CCID.S35252 PMid:23637546 PMCid:PMC3639020 